\title{
Breast carcinoma in situ: An observational study of tumor subtype, treatment and outcomes
}

\author{
Qi Wu ${ }^{1}$, Juanjuan $\mathrm{Li}^{1}$, Si Sun ${ }^{2}$, Shan Zhu ${ }^{1}$, Chuang Chen ${ }^{1}$, Juan Wu ${ }^{3}$, Qian Liu ${ }^{1}$, Wen \\ Wei $^{1}$ and Shengrong Sun ${ }^{1}$ \\ ${ }^{1}$ Department of Breast and Thyroid Surgery, Renmin Hospital of Wuhan University, Wuhan, Hubei, P. R. China \\ ${ }^{2}$ Department of Clinical Laboratory, Renmin Hospital of Wuhan University, Wuhan, Hubei, P. R. China \\ ${ }^{3}$ Department of Pathology, Renmin Hospital of Wuhan University, Wuhan, Hubei, P. R. China \\ Correspondence to: Shengrong Sun, email: sun137@sina.com
}

Keywords: breast carcinoma in situ, tumor subtype, treatment, outcomes

Received: September 14,2016 Accepted: November 23,2016 Published: December 02, 2016

\section{ABSTRACT}

Background \& Aims: To evaluate the clinical presentation, treatment and outcome of patients with breast carcinoma in situ (BCIS) with special emphasis on the role of the tumor subtype and local treatment in these patients.

Methods: Using data obtained by the Surveillance, Epidemiology, and End Results (SEER) program from 2010-2013, a retrospective, population-based cohort study was conducted to investigate tumor subtype-specific differences in various characteristics, overall survival (OS) and breast cancer-specific mortality (BCSM).

Results: In all, 6867 patients with BCIS were eligible during the 2010-2013 study period. Compared with the hormone receptor (HoR)+/HER- subgroup, patients with triple negative (TN) breast cancer were more likely to have tumors that were higher in grade and larger in size; they were also more likely to have tumors with ductal and comedo histology and were less likely to have tumors with cribriform and papillary histology (each $P<0.05$ ). During the follow-up period, patients with TN breast cancer had an OS of $97.0 \%$ compared with $98.6 \%$ in the HoR+/HER- subgroup $(P<0.05)$. Furthermore, the BCSM rate was $1.0 \%$ for the TN group compared with $0.1 \%$ for the HoR+/HER- subgroup $(P<0.05)$. Multivariate analysis revealed that patients with TN MBC had a poorer OS and BCSM $(P<0.05)$. Multivariate analysis of OS with respect to the local treatment history showed that patients who received breast-conserving surgery $(B C S)$ combined with radiotherapy $(R)$ were more likely to have an improved OS $(P<0.05)$. Moreover, the results demonstrated that patients who underwent SLNB were more likely to have a lower BCSM $(P<0.05)$.

Conclusions: The results demonstrate that BCIS appears to alter the prognosis associated with the TN subtype. Meanwhile, BCS plus R was a preferable option and resulted in survival rates that were better than those achieved with mastectomy; thus, SLNB should be considered as an appropriate assessment of axillary staging in patients with BCIS.

\section{INTRODUCTION}

The term breast carcinoma in situ (BCIS) encompasses lesions that contain abnormal epithelial cells that are completely confined within breast lobules and/or ducts without invasion beyond the basement membrane. BCIS includes a variety of pathological types. The 2 major types of breast carcinoma in situ are ductal carcinoma in situ (DCIS) and lobular carcinoma in situ (LCIS). The incidence of BCIS increased rapidly after the introduction of mammography as a population screening tool and has subsequently increased at a slower rate [1-4].

In the majority of patients, BCIS is primarily viewed as an indicator of an increased risk for invasive breast cancer. Moreover, several studies have revealed that BCIS lesions tend to be small in size, grade II or III, and widely positive for estrogen receptor (ER) and progesterone receptor (PR), but HER2 testing is not a routine part of the pathologic evaluation $[5,6]$. However, studies have also suggested that high nuclear grade DCIS lesions are 
often negative for ER and that they overexpress HER2. Furthermore, this subtype may be associated with reduced survival, and thus targeting HER2 is a potential treatment strategy for HER2-overexpressing DCIS. Additionally, a new Van Nuys Prognostic Index (VNPI) is used as an independent predictor of local recurrence; this new index has a new formula that accounts for tumor size, margin width, pathologic classification, and age [7].

Traditional treatment has been mastectomy, whereas breast-conserving surgery (BCS) is a feasible surgical option for select patients. In addition to BCS, the effect of sentinel lymph node biopsy (SLNB) in BCIS remains unclear. Based on the current standards, SLNB has been recommended as a less invasive method compared with axillary lymph node dissection (ALND) for the staging of patients with early invasive ductal carcinoma. We speculate that SLNB might be approved as an effective method to detect axillary lymph nodes (ALNs) in patients with BCIS. The benefit of radiotherapy in terms of a significantly reduced risk of local recurrence (LR) in those who receive $\mathrm{BCS}$ has been demonstrated by several large randomized controlled trials $[8,9]$. However, the idea that radiotherapy should be avoided in selected low-risk cases remains uncertain.

The clinical characteristics of BCIS and the optimal approaches to treatment are topics of uncertainty and concern for both patients and clinicians. Therefore, this article will evaluate the clinical presentation, treatment and outcomes of patients with BCIS, with special stress on the role of breast cancer subtype, BCS and SLNB.

\section{RESULTS}

\section{Clinical and tumor characteristics}

In all, 6867 patients with BCIS were eligible during the 2010-2013 study period. We excluded 54,190 patients whose medical records did not contain information on breast cancer subtype and 241 patients whose survival times were classified as unknown in the analysis. Information was available for 4324 patients with BCIS in the HoR+/HER-subgroup, 1409 patients in the HoR+/HER+ subgroup, 795 patients in the HoR-/HER+ subgroup and 429 patients in the triple-negative (TN) subgroup, who were all included in this study.

Differences in patient demographics, cancer characteristics, treatments, and outcomes among the subgroups are summarized in Table 1. Compared with the HoR+/HER- subgroup, patients with TN breast cancer were more likely to have tumors that were higher in grade and larger and were more likely to have tumors with ductal and comedo histology; these patients were less likely to have tumors with cribriform and papillary histology (each
A

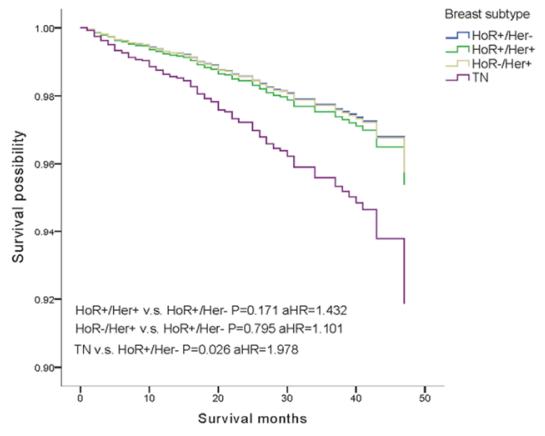

B

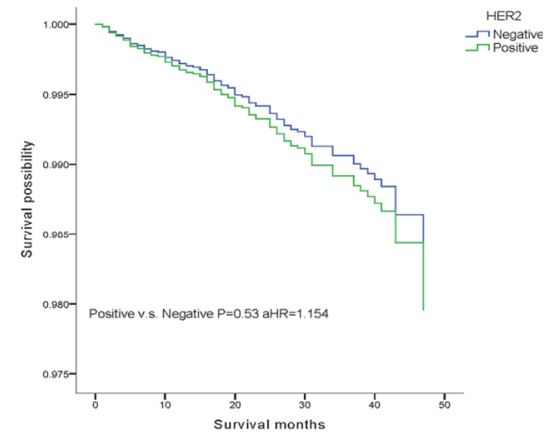

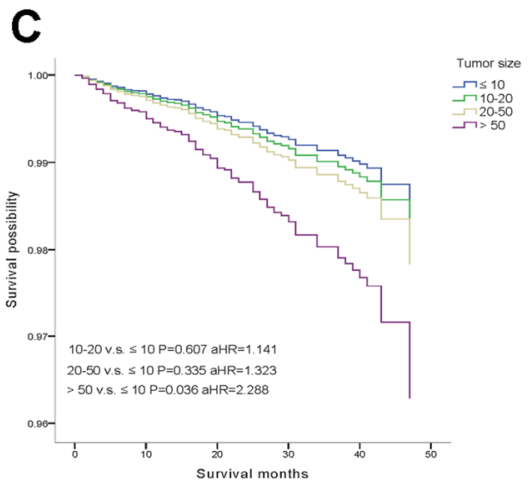
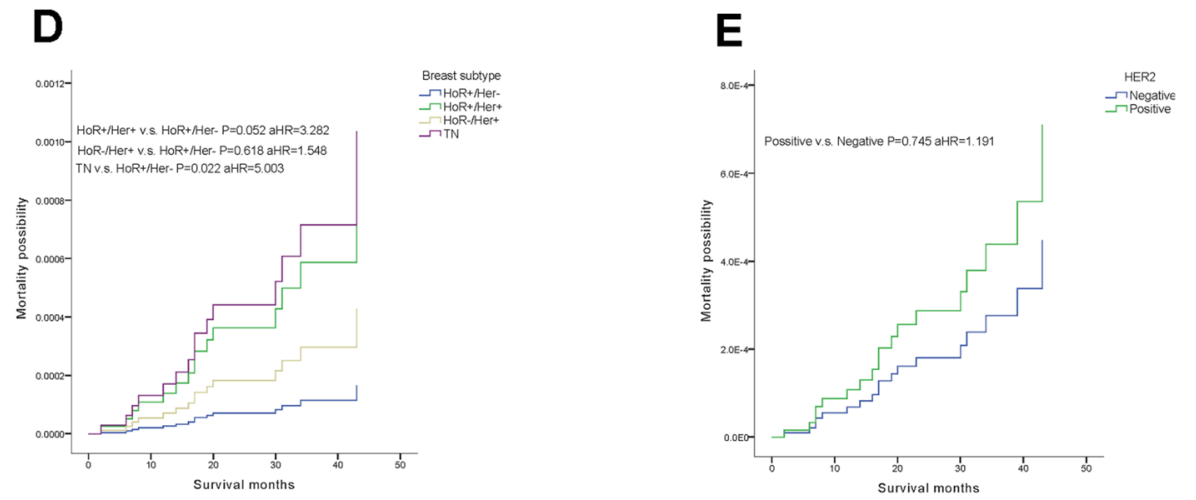

Figure 1: Weighted Kaplan-Meier curves of overall survival(OS) and breast-cancer-specific mortality(BCSM). A. OS is based on tumor subtype. B. OS is based on HER2 status. C. OS is based on tumor size. D. BCSM is based on tumor subtype. E. BCSM is based on HER2 status. 
Table 1: Patient characteristics within subgroups

\begin{tabular}{|c|c|c|c|c|c|}
\hline Variables & $\begin{array}{l}\text { HoR+/HER- } \\
\text { N=4324(\%) }\end{array}$ & $\begin{array}{r}\text { HoR+/HER+ } \\
\text { N=1409(\%) }\end{array}$ & $\begin{array}{c}\text { HoR-/HER+ } \\
\mathrm{N}=705(\%)\end{array}$ & $\begin{array}{l}\text { TN } \\
\mathrm{N}=429(\%)\end{array}$ & P value ${ }^{*}$ \\
\hline Follow-up(months) & $21.61 \pm 13.93$ & $21.67 \pm 14.19$ & $21.59 \pm 13.57$ & $23.31 \pm 13.91$ & \\
\hline Age at diagnosis, y & & & & & $\mathrm{P}<0.001$ \\
\hline$<35$ & $28(0.6)$ & $14(1.0)$ & $5(0.7)$ & $0(0.0)$ & \\
\hline $35-49$ & $883(20.4)$ & $335(23.8)$ & $128(18.2)$ & $68(15.9)$ & \\
\hline $50-64$ & $1747(40.4)$ & $642(45.6)$ & $322(45.7)$ & $173(40.3)$ & \\
\hline$\geq 65$ & $1666(38.5)$ & $418(29.7)$ & $350(35.5)$ & $188(43.8)$ & \\
\hline Sex & & & & & 0.039 \\
\hline Female & $4298(99.4)$ & $1402(99.5)$ & $705(100)$ & $428(99.6)$ & \\
\hline Male & $26(0.6)$ & $7(0.5)$ & $0(0.0)$ & $1(0.4)$ & \\
\hline Race & & & & & $\mathrm{P}<0.001$ \\
\hline white & $3307(76.5)$ & $1110(78.8)$ & $575(81.6)$ & $333(77.6)$ & \\
\hline Black & $62(14.5)$ & $170(12.1)$ & $62(8.8)$ & $60(14.0)$ & \\
\hline Other & $351(8.1)$ & $115(8.2)$ & $62(8.8)$ & $34(7.9)$ & \\
\hline Unknown & $39(0.9)$ & $14(1.0)$ & $6(0.9)$ & $2(0.5)$ & \\
\hline CHSDA Region & & & & & 0.197 \\
\hline East & $2225(51.5)$ & $702(49.8)$ & $330(46.8)$ & $205(47.8)$ & \\
\hline Northern Plains & $541(12.5)$ & $190(13.5)$ & $99(14.0)$ & $54(12.6)$ & \\
\hline Pacific Coast & $1452(33.6)$ & $475(33.7)$ & $256(36.3)$ & $156(36.4)$ & \\
\hline Southwest & $106(2.5)$ & $42(3.0)$ & $19(2.7)$ & $13(3.0)$ & \\
\hline Alaska & $0(0)$ & $0(0)$ & $1(0.1)$ & $1(0.2)$ & \\
\hline Grade & & & & & $\mathrm{P}<0.001$ \\
\hline Well & $772(17.9)$ & $71(5.0)$ & $8(1.1)$ & $15(3.5)$ & \\
\hline Moderately & $1798(41.6)$ & $371(26.3)$ & $70(9.9)$ & $82(19.1)$ & \\
\hline Poorly & $1014(23.5)$ & $707(50.2)$ & $488(69.2)$ & $257(59.9)$ & \\
\hline Undifferentiated & $102(2.4)$ & $80(5.7)$ & $60(8.5)$ & $26(6.1)$ & \\
\hline Unknown & $638(14.8)$ & $180(12.8)$ & $79(11.2)$ & $49(11.4)$ & \\
\hline Histology & & & & & $\mathrm{P}<0.001$ \\
\hline Ductal & $1694(39.2)$ & $621(44.1)$ & $285(40.4)$ & 204(47.6) & \\
\hline Lobular & $148(3.4)$ & $22(1.6)$ & $6(0.9)$ & $9(2.1)$ & \\
\hline Ductal and Lobular & $107(2.5)$ & $25(1.8)$ & $5(0.7)$ & $8(1.9)$ & \\
\hline $\begin{array}{l}\text { Ductal with other } \\
\text { types }\end{array}$ & $1339(31.0)$ & $436(30.9)$ & $190(27.0)$ & $101(23.5)$ & \\
\hline Paget disease & $2(0)$ & $11(0.8)$ & $19(2.7)$ & $3(0.7)$ & \\
\hline Comedo & $288(6.7)$ & $179(12.7)$ & $165(23.4)$ & $76(17.7)$ & \\
\hline Cribriform & $448(10.4)$ & $65(4.6)$ & $20(2.8)$ & $12(2.8)$ & \\
\hline
\end{tabular}




\begin{tabular}{|c|c|c|c|c|c|}
\hline Papillary & $239(5.5)$ & $39(2.8)$ & $8(18.1)$ & $8(1.9)$ & \\
\hline Intracystic & $49(1.1)$ & $5(0.4)$ & $1(1.1)$ & $0(0)$ & \\
\hline Others & $10(0.2)$ & $6(0.4)$ & $6(0.9)$ & $8(1.9)$ & \\
\hline Tumor size(mm) & & & & & $\mathrm{P}<0.001$ \\
\hline$\leq 10$ & $2700(62.4)$ & $788(55.9)$ & $334(47.4)$ & 214(49.9) & \\
\hline $10-20$ & $876(20.3)$ & $302(21.4)$ & $187(26.5)$ & $116(27.0)$ & \\
\hline $20-50$ & $587(13.6)$ & $240(17.0)$ & $147(20.9)$ & $81(18.9)$ & \\
\hline$>\mathbf{5 0}$ & $161(3.7)$ & $79(5.6)$ & $37(5.2)$ & $18(4.2)$ & \\
\hline Laterality & & & & & 0.505 \\
\hline Left & $2264(52.4)$ & $723(51.3)$ & $383(54.3)$ & 201(46.9) & \\
\hline Right & $2059(47.6)$ & $686(48.7)$ & $322(45.7)$ & $228(53.1)$ & \\
\hline Radiotherapy & & & & & $\mathrm{P}<0.001$ \\
\hline No & $2218(51.3)$ & $667(48.0)$ & $360(51.1)$ & $204(47.6)$ & \\
\hline Yes & $2001(46.3)$ & $690(49.0)$ & $321(45.5)$ & $216(50.3)$ & \\
\hline Unknown & $105(2.4)$ & $42(3.0)$ & $24(3.4)$ & $9(2.1)$ & \\
\hline Surgery & & & & & $\mathrm{P}<0.001$ \\
\hline Mastectomy & $1283(29.7)$ & $493(35.0)$ & $274(38.9)$ & $154(35.9)$ & \\
\hline BCS & 2923(67.6) & $876(62.2)$ & $407(57.7)$ & $266(62.0)$ & \\
\hline Unknown & $118(2.7)$ & $40(2.8)$ & $24(3.4)$ & $9(2.1)$ & \\
\hline LN surgery & & & & & $\mathrm{P}<0.001$ \\
\hline SLNB & $4082(94.4)$ & $1325(94.0)$ & $649(92.1)$ & $393(91.6)$ & \\
\hline ALND & $198(4.6)$ & $76(5.4)$ & $44(6.2)$ & $31(7.5)$ & \\
\hline Unknown & $44(1.0)$ & $8(0.6)$ & $12(1.7)$ & $4(0.9)$ & \\
\hline Status & & & & & $\mathrm{P}<0.001$ \\
\hline Alive & 4263(98.6) & $1387(98.4)$ & $695(98.6)$ & $416(97.0)$ & \\
\hline Dead & $61(1.4)$ & $22(1.6)$ & $10(1.4)$ & $13(3.0)$ & \\
\hline Breast cancer & $6(0.1)$ & $6(0.4)$ & $3(0.3)$ & $4(1.0)$ & \\
\hline Other & $55(1.3)$ & $16(1.2)$ & $7(1.1)$ & $9(2.0)$ & \\
\hline
\end{tabular}

* P values calculated by Pearson Chi squared testing; Bold if statistically significant, $\mathrm{P}<0.05$

y: years, mm: millimeter, y: years, BCS: breast-conserving surgery, HoR: hormone receptor, TN: triple negative, LN: lymph node, SLNB: sentinel lymph node biopsy, ALND: axillary lymph node dissection.

$P<0.05)$. Patients within the HoR-/HER+ subgroup had tumors that were, in general, higher in grade and larger in size compared with tumors of patients in the HoR+/ HER- subgroup. Furthermore, patients in the HoR-/ HER + subgroup were the most likely to have tumors with comedo and papillary histology. With respect to treatment options, patients within the four subgroups tended to receive breast-conserving surgery (BCS) and sentinel lymph node biopsy (SLNB).

\section{Survival analysis}

A weighted Kaplan-Meier analysis was used to determine overall survival (OS) and breast cancer-specific mortality (BCSM), which were based on breast cancer subtype and HER2 status, of the patients in the subgroups. Survival curves for the subgroups were generated (Figure 1). At the median follow-up of 22 months, patients with TN breast cancer had an OS of $97.0 \%$ compared with 
Table 2: Cox proportional hazards regression model analysis of overall survival (OS) and breast cancer-specific mortality (BCSM)

\begin{tabular}{|c|c|c|c|c|}
\hline \multirow[t]{2}{*}{ Variables } & \multicolumn{2}{|l|}{ OS } & \multicolumn{2}{|l|}{ BCSM } \\
\hline & $\operatorname{aHR}(95 \% \mathrm{CI})$ & P-value & $\operatorname{aHR}(95 \% \mathrm{CI})$ & P-value \\
\hline \multicolumn{5}{|l|}{ Age at diagnosis, $y$} \\
\hline$<35$ & Reference & & Reference & \\
\hline $35-49$ & $501.3(0.0,2.393)$ & 0.171 & $980.6(0.0,6.91 \mathrm{E} 96)$ & 0.95 \\
\hline $50-64$ & $1240.3(0.0,2.275)$ & 0.795 & $1103.7(0.0,7.75 \mathrm{E} 96)$ & 0.949 \\
\hline$\geq 65$ & $4086.3(0.0,3.605)$ & 0.061 & $3567.1(0.02,2.5 \mathrm{E} 97)$ & 0.941 \\
\hline \multicolumn{5}{|l|}{ Sex } \\
\hline Female & Reference & & Reference & \\
\hline Male & $0.0(0.0,6.4 \mathrm{E} 48)$ & 0.898 & $0.56(0.0,5.9 \mathrm{E} 135)$ & 0.959 \\
\hline \multicolumn{5}{|l|}{ Race } \\
\hline white & Reference & & Reference & \\
\hline Black & $0.608(0.321,1.153)$ & 0.128 & $0.56(0.12,2.617)$ & 0.461 \\
\hline \multicolumn{5}{|l|}{ Grade } \\
\hline Well & Reference & & Reference & \\
\hline Moderately & $0.903(0.493,1.653)$ & 0.74 & $0.697(0.123,3.996)$ & 0.684 \\
\hline Poorly & $0.662(0.338,1.293)$ & 0.228 & $1.008(0.188,5.408)$ & 0.993 \\
\hline Undifferentiated & $1.024(0.353,2,969)$ & 0.965 & $1.176(0.091,15.175)$ & 0.901 \\
\hline \multicolumn{5}{|l|}{ Histology } \\
\hline Ductal & Reference & & Reference & \\
\hline Lobular & $0.785(0.234,2.629)$ & 0.695 & $0.001(0.0,9,7 \mathrm{E} 42)$ & 0.125 \\
\hline Ductal and Lobular & $0.371(0.051,2.713)$ & 0.329 & $0.0(0.0,2,7 \mathrm{E} 61)$ & 0.563 \\
\hline $\begin{array}{l}\text { Ductal with other } \\
\text { types }\end{array}$ & $0.909(0.554,1.489)$ & 0.704 & $1.164(0.369,3.67)$ & 0.563 \\
\hline Paget disease & $1.807(0.412,7.926)$ & 0.443 & $0.0(0.0,4.9 \mathrm{E} 105)$ & 0.125 \\
\hline Comedo & $1.341(0.717,2.508)$ & 0.359 & $1.226(0.309,4.86)$ & 0.563 \\
\hline Cribriform & $0.547(0.214,1.397)$ & 0.207 & $0.001(0.0,9.5 \mathrm{E} 27)$ & 0.563 \\
\hline Papillary & $1.158(0.511,2.625)$ & 0.725 & $1.282(0.152,10.802)$ & 0.125 \\
\hline Intracystic & $0.689(0.091,5.238)$ & 0.719 & $0.0(0.0,8.1 \mathrm{E} 116)$ & 0.563 \\
\hline Others & $0.0(0.0,3.9 \mathrm{E} 56)$ & 0.91 & $0.0(0.0,4.2 \mathrm{E} 164)$ & 0.563 \\
\hline \multicolumn{5}{|l|}{ Tumor size(mm) } \\
\hline$\leq \mathbf{1 0}$ & Reference & & Reference & \\
\hline $10-20$ & $1.141(0.69,1.889)$ & 0.607 & $0.235(0.029,1.892)$ & 0.174 \\
\hline 20-50 & $1.323(0.749,2.337)$ & 0.335 & $0.981(0.243,3.961)$ & 0.978 \\
\hline$>\mathbf{5 0}$ & $2.288(1.055,4.963)$ & 0.036 & $1.688(0.317,9.001)$ & 0.54 \\
\hline \multicolumn{5}{|l|}{ ER } \\
\hline Negative & Reference & & Reference & \\
\hline
\end{tabular}




\begin{tabular}{lllll}
\hline Positive & $1.302(0.694,2.441)$ & 0.411 & $1.481(0.41,5.353)$ & 0.549 \\
PR & & & & \\
Negative & Reference & & Reference & \\
Positive & $0.577(0.332,1.002)$ & 0.051 & $0.314(0.089,1.107)$ & 0.072 \\
HER2 & & & & \\
Negative & Reference & & Reference & \\
Positive & $1.154(0.739,1.802)$ & 0.53 & $1.191(0.415,3.418)$ & 0.745 \\
Subtype & & & & \\
HoR+/HER- & Reference & & Reference & \\
HoR+/HER+ & $1.432(0.857,2.393)$ & 0.171 & $3.282(0.989,10.888)$ & 0.052 \\
HoR-/HER+ & $1.101(0.533,2.275)$ & 0.795 & $1.548(0.279,8.598)$ & 0.618 \\
TN & $1.978(1.087,3.60)$ & 0.026 & $5.003(1.263,19.821)$ & 0.022 \\
Radiotherapy & & & & \\
No & Reference & & Reference & \\
Yes & $0.303(0.18,0.51)$ & P < 0.001 & $0.466(0.104,2.098)$ & 0.32 \\
Treatment & & & & \\
Mastectomy & Reference & & Reference & \\
BCS & $1.707(1.005,2.899)$ & 0.048 & $0.979(0.226,4.242)$ & 0.977 \\
BCS+R & $0.499(0.286,0.869)$ & 0.014 & $0.295(0.073,1.198)$ & 0.088 \\
LN surgery & & & & \\
SLNB & Reference & & Reference & \\
ALND & $1.677(0.828,3.399)$ & 0.151 & $3.902(1.104,13.788)$ & 0.035 \\
\hline
\end{tabular}

* P values calculated by Log-rank testing; Bold if statistically significant, $\mathrm{P}<0.05$

BCS: breast-conserving surgery, R: Radiotherapy, HoR: hormone receptor, TN: triple negative, LN: lymph node, SLNB: sentinel lymph node biopsy, ALND: axillary lymph node dissection.

aHR: adjusted hazard ratio (adjusted for age at diagnosis, race, grade, histology, tumor size, laterality, ER, PR, HER2, subtype, radiotherapy, treatment and LN surgery).

patients in the HoR+/HER- subgroup who had an OS of $98.6 \%(P<0.05)$. In addition, the BCSM rate was $1.0 \%$ for the TN group compared with $0.1 \%$ for the HoR + HERsubgroup $(P<0.05)$.

We used a multivariate analysis based on the weighted Kaplan-Meier results. All the prognostic factors that predicted OS and BCSM were analyzed in a multivariate analysis (Table 2). In the multivariate analysis, patients with TN breast cancer were more likely to have a poorer OS and a higher BCSM compared with patients in the HoR+/HER- subgroup, as shown in Figure $1 \mathrm{~A}, 1 \mathrm{D}(\mathrm{OS}, P=0.026$, aHR $=1.978 ; \mathrm{BCSM}, P=0.022$, $\mathrm{aHR}=5.003)$. Unexpectedly, these findings showed a decreased OS only in the subgroup of patients whose tumor size was $>50$ (Figure 1C, OS, $P=0.036$, aHR $=$ 2.288; BCSM, $P=0.54$, aHR $=1.688)$. Furthermore,
HER2 status was not associated with OS or BCSM (Figure $1 \mathrm{~B}, 1 \mathrm{E}, \mathrm{OS}, P=0.53$, aHR $=1.154$; BCSM, $P=0.745$, $\mathrm{aHR}=1.191)$.

\section{Effect of surgical treatment on survival outcomes}

We characterized three subgroups, based on different local treatments, as follows: mastectomy, BCS only and BCS with radiotherapy $(\mathrm{BCS}+\mathrm{R})$ (Table 2, Figure 2). During the follow-up period, a multivariate analysis of OS based on local treatment history showed that patients who underwent BCS combined with radiotherapy (R) were more likely to experience an improved OS compared with those who underwent mastectomy $(P=0.014$, aHR $=0.499$ ). Additionally, patients who underwent BCS only 
tended to have a lower OS (Figure 2A, $P=0.048$, aHR $=$ 1.707). We also used the analysis to examine the option of radiotherapy, which showed that patients who underwent radiotherapy had a higher OS that did not affect the BCSM (Figure 2B, 2D, OS, $P<0.001$, aHR $=0.303$; BCSM, $P=$ 0.32 , aHR $=0.466$ ). However, the results demonstrated a significant difference within the LN surgery only group in terms of BCSM, and patients who underwent SLNB were more likely to have a lower BCSM (Figure 2E, $P=0.035$, $\mathrm{aHR}=3.902$ ).

\section{DISCUSSION}

In this large population-based cohort of cases diagnosed with BCIS, we found a poorer survival in patients with the TN subtype after adjustment for other factors. In addition, our analysis of tumor size demonstrated a tumor size $>50 \mathrm{~mm}$ was more likely to augment the OS of patients with BCIS. In our series, a dramatic difference was observed within the surgical treatment and radiotherapy subgroups with respect to OS, where patients who underwent SLNB were more likely to have a lower BCSM.

In previous studies, nuclear grade, tumor size and age were all important factors that could be used to predict local recurrence in patients with BCIS [10, 11]. However, our research revealed that nuclear grade and age were not prognostic factors for OS or BCSM, and our findings showed a decreased OS only in patients with a tumor size $>50$. In the current study, patients in the HoR-/ HER + subgroup had tumors that were generally higher in grade and larger in size compared with tumors of patients in the HoR+/HER- subgroup. The correlation between HER2 and tumor behavior has been previously described. One study revealed that HER2 was overexpressed in 24/31 (77\%) patients with DCIS who experienced local relapse [12]. In contrast, another study showed that HER2 overexpression may not be the key factor in the progression of DCIS to invasive carcinoma and that HER2 gene amplification is inversely related to invasive progression in patients with DCIS $[13,14]$. However, the precise incidence of HER2 overexpression in many cases of DCIS is unclear. A retrospective analysis was performed and showed that HER2 was overexpressed in $61 \%$ of cases of DCIS [15]. In contrast, Roses et al. [16] reported 106 patients with DCIS and noted HER2 overexpression in only $37 \%$ of cases. They also described an association between HER2 overexpression and the detection of invasive foci in surgical specimens. However, we analyzed common prognostic factors as well as HER2 status, and
A

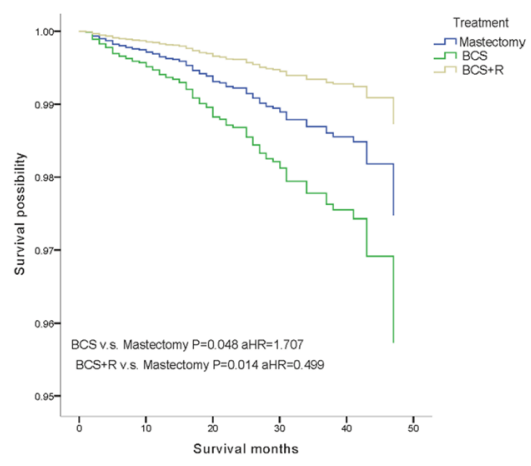

B

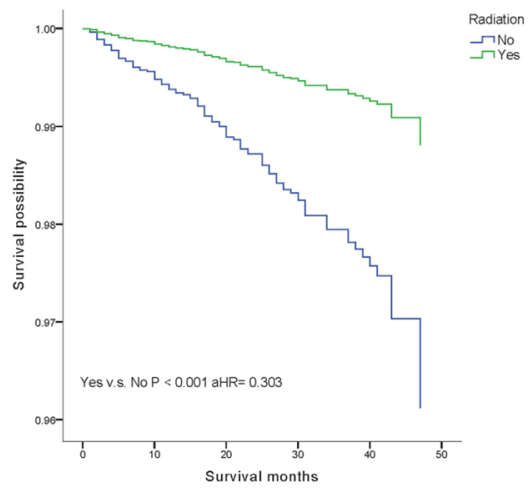

C

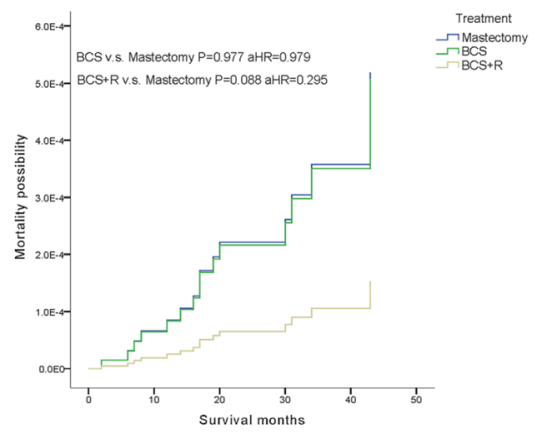

D

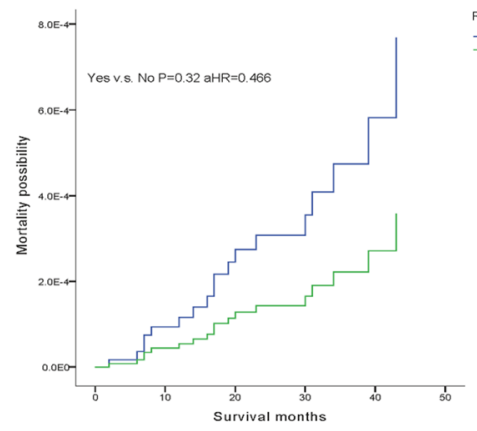

E

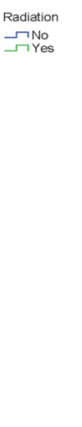

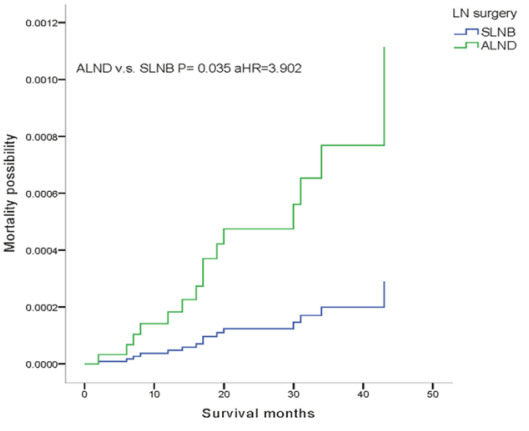

Figure 2: Weighted Kaplan-Meier curves of overall survival(OS) and breast-cancer-specific mortality(BCSM) in subgroup analysis. A. OS is based on treatment. B. OS is based on radiotherapy. C. BCSM is based on treatment. D. BCSM is based on radiotherapy. E. BCSM is based on lymph node (LN) surgery. 
the results showed that HER2 status was not correlated with survival after adjustment for other prognostic factors. This conclusion remains to be confirmed by a future prospective trial.

Triple-negative (TN) BCIS was seldom diagnosed; this may be because tumors of the TN subtype progress quickly. Therefore, our study reported that patients with $\mathrm{TN}$ breast cancer tended to have tumors that were higher in grade and larger in size; their tumors were also more likely to have ductal and comedo histology, and their prognosis was more likely to be poor. In contrast to a previous study, our study reported that tumors of the TN subtype may progress much faster than other tumor types [14]. Some reports have suggested that TN BCIS may be a potential precursor to TN invasive cancer $[17,18]$, and a more frequent and rapid progression from BCIS to invasive cancer was found to be related to the comedo histologic subtype of BCIS [19, 20]. Consequently, some unrecognized mechanisms or features that promote the progression of the TN subtype should be further studied.

The surgical treatment of BCIS is controversial. Although mastectomy has been demonstrated to be curative for approximately all patients with BCIS [21, 22], mastectomy represented significant overtreatment for the majority of cases detected by the current methods. When BCS was elected rather than mastectomy, radiotherapy statistically decreased local recurrence rates compared with BCS alone [23]; nevertheless, radiotherapy may also represent overtreatment for low-risk patients. Several studies revealed that local excision only was an appropriate surgery for patients with low-risk BCIS $[7,24]$. However, BCS plus radiation for moderately or high-risk patients was the consensus. A retrospective study showed that the overall survival was similar for all three subgroups (BCS alone, $\mathrm{BSC}+\mathrm{R}$ and mastectomy), but the addition of radiation to BCS decreased the LR from $43 \%$ to $7 \%$ [25]. In addition, several retrospective studies[26-30] reported the survival outcome of patients with DCIS who were managed by BCS with or without radiotherapy and mastectomy. As expected, BCS alone resulted in consistently higher rates of LR (range, 8\%$34 \%$ ) compared with patients treated by BCS $+\mathrm{R}$ (range, 0\%-17\%). Our results also demonstrated that patients who underwent $\mathrm{BCS}+\mathrm{R}$ were more likely to exhibit an improved OS, and patients who underwent BCS alone tended to have a lower OS compared with those in the mastectomy subgroup. Therefore, the recommendation of BCS combined with radiotherapy was the preferable alternative for patients with BCIS. As in the cited studies, axillary metastases were observed in approximately 1-2\% of BCIS cases [31]. Due to the associated increased risk of coexisting microinvasion, the need for axillary staging becomes more relevant[32, 33]. SLNB, which was used as an approach in the common population of patients with BCIS, appeared to be feasible [34-36]. In the present study, patients who underwent SLNB exhibit a similar survival with those who received ALND regardless of the surgical method. Likewise, our results reported that patients treated by SLNB had a similar OS and better BCSM in comparison with those who received ALND. Future studies are warranted to determine the potential benefits of SLNB in patients with BCIS.

When the molecular profiles of BCIS are considered, some studies confirmed that BCIS demonstrated high expression of estrogen receptor (ER), which was associated with low-grade lesions, but these tumors were positive for c-erbB-2, Ki-67 and p53, the expression of which is associated with high-grade lesions [31, 37, 38]. A recent case-control study suggested that BCIS cases that were triple-positive for p16, COX-2 and Ki67 had a significantly higher rate of progression to invasive breast cancer than those that were negative for these biomarkers (8-year risks for subsequent invasive cancer were 19.6\% and $4.1 \%$, respectively) [39]. Simultaneously, several studies confirmed that HoR negativity, high S-phase fraction, abnormal DNA ploidy, p53 overexpression and HER2 overexpression were associated with more aggressive tumor behavior in BCIS [40-43]. Geneexpression profiling is likely to enhance our understanding of BCIS behavior and its relationship to invasive breast cancer. Findings of several studies [40, 44, 45] recorded differential expression patterns and identified new facets of the earliest stage of breast-cancer progression. More molecular and genetic studies that predict local recurrence and progression to invasive breast cancer independent of standard prognostic markers are required, and the difference in survival must continue to be monitored.

The main limitations of this study were the heterogeneous population and its retrospective setting. The information on systemic therapy and margin control was insufficient, and the follow-up was limited. As a result, HER2 targeted therapy and novel adjuvant hormone therapy remained in use for the management of BCIS to significantly improve the survival. Additionally, we had no specific information on the type of axillary surgery, and thus we substituted the number of lymph nodes removed.

Despite the limitations, our study demonstrates that BCIS appears to alter the prognosis associated with the TN subtype. Moreover, BCS plus R was the preferable option and resulted in survival rates better than those achieved with mastectomy. SLNB should be considered as an appropriate assessment of axillary staging in patients with BCIS.. However, the surgical treatment plan must be chosen for its strength in aiding the clinical and imaging assessment. Further studies are needed to minimize variation in modes of treatment and to establish a standardized management approach. 


\section{MATERIALS AND METHODS}

\section{Data source and study design}

We collected data obtained between 2010 and 2013 from the National Cancer Institute's Surveillance, Epidemiology, and End Results (SEER) program. SEER began to collect information on HER2 status in 2010. Therefore, we used that year as the starting point. We used the International Classification of Diseases for Oncology, 3rd edition (ICD-O-3) histopathology codes to extract all cases with BCIS (codes 8201, 8230, 8500 through 8507, 8523 ). ICD-O-3 codes were also used to categorize BCIS cases by subtype (DCIS, not otherwise specified [8500, 8523], comedo carcinoma [8501], papillary [8503], micropapillary [8507], cribriform [8201], solid [8230], other [8502, 8504-8506] and LCIS [8520, 8524]) based on a scheme that has been previously described [46]. We selected cases with known hormone receptor (HoR) status and HER2 status. Patients who underwent surgery, those with an unknown type of breast cancer and patients who were diagnosed at autopsy were excluded.

Demographic variables included age at diagnosis $(<$ $35,35-49,50-64,>65$ years) and race (white, black, other). Cancer characteristics were classified according to grade (well, moderately, poorly, undifferentiated, unknown), tumor size $(\leq 10,10-20,20-50,>50 \mathrm{~mm})$, laterality (right, left, others, unknown), HoR status and HER2 status (positive, negative, borderline, unknown). Treatment characteristics included receipt of radiation therapy (no, yes, unknown). The subtypes were characterized according to the breast subtype variable as either $\mathrm{HoR}+/$ HER2-, HoR+/HER2+, HoR-/HER2+ or triple-negative (TN). Patients were categorized according to whether they underwent BCS (surgery of primary site variable values of 20-24) or mastectomy (surgery of primary site variable values of 30-80). Since the type of axillary surgery was not reported within the SEER database, the patients who had 1-5 lymph nodes removed were regarded as the sentinel lymph node biopsy (SLNB) group and those with $>5$ lymph nodes that were removed were regarded as the axillary lymph node dissection (ALND) group, as in previous studies [47].

The two primary outcomes in our study were overall survival (OS) and breast cancer-specific mortality (BCSM). Vital stats were reported as either "alive" or "dead" in the SEER dataset. The survival time (in months) was calculated for each patient using the "Completed Months of Follow-up" given in the SEER database. The overall survival (OS) was determined by patients who were alive at the end of the study period or who were alive at their last follow-up. Breast cancer-specific mortality (BCSM) was determined by a comparison of patients whose cause of death was due to breast cancer with patients who were alive at the end of the study period, those who had died from other causes, or who were alive at their last follow-up. Cases without survival times were classified as unknown and were removed from the study.

\section{Statistical analysis}

Patient demographics and cancer- and treatmentrelated characteristics were compared among the subgroups using Chi square or Fisher's exact tests. Survival outcomes on OS and BCSM were estimated using the weighted Kaplan-Meier method, and variables were compared among the subgroups using the log-rank test. Univariate and multivariate Cox proportional hazard regressions were used to obtain hazard ratios (HRs) and their respective $95 \%$ confidence intervals to show the strength of the estimated relative risk; these approaches were applied to model the relationship between potential covariates and either OS or BCSM. All statistical analyses and all charts of survival probabilities were performed with SPSS 19.0 (IBM Corporation, Armonk, NY, USA). A two-sided $P$ value $<0.05$ was considered statistically significant.

\section{ACKNOWLEDGMENTS}

This work was partially supported by a National Natural Science Foundation of China (NSFC) grant (Grant NO: 81471781) and a National major scientific instruments and equipment development projects (Grant NO: 2012YQ160203) to Dr. Shengrong Sun. This work was also supported by an NSFC grant to Dr. Juanjuan Li (Grant NO: 81302314/H1622), a Fundamental Research Funds of Hubei Province Health and Family Planning Commission grant to Wen Wei (Grant NO: JS-20110118) and a Fundamental Research Funds for the Central Universities of China grant to Shan Zhu (Grant NO: 2042014kf0189).

\section{CONFLICTS OF INTEREST}

The authors have no conflicts of interest to disclose.

\section{REFERENCES}

1. Virnig BA, Tuttle TM, Shamliyan T and Kane RL. Ductal carcinoma in situ of the breast: a systematic review of incidence, treatment, and outcomes. J Natl Cancer Inst. 2010; 102(3):170-178.

2. Joslyn SA. Ductal carcinoma in situ: trends in geographic, temporal, and demographic patterns of care and survival. Breast J. 2006; 12(1):20-27.

3. Kerlikowske K. Epidemiology of ductal carcinoma in situ. J Natl Cancer Inst Monogr. 2010; 2010(41):139-141. 
4. Isik A, Karavas E, Peker K, Soyturk M and Yilmaz I. Male Mondor's Disease is a Rare Entity. Breast J. 2016.

5. Ward EM, DeSantis CE, Lin CC, Kramer JL, Jemal A, Kohler B, Brawley OW and Gansler T. Cancer statistics: Breast cancer in situ. CA Cancer J Clin. 2015; 65(6):481495 .

6. Zhou W, Jirstrom K, Amini RM, Fjallskog ML, Sollie $\mathrm{T}$, Lindman H, Sorlie T, Blomqvist $\mathrm{C}$ and Warnberg F. Molecular subtypes in ductal carcinoma in situ of the breast and their relation to prognosis: a population-based cohort study. BMC Cancer. 2013; 13:512.

7. Silverstein MJ. The University of Southern California/Van Nuys prognostic index for ductal carcinoma in situ of the breast. Am J Surg. 2003; 186(4):337-343.

8. Vapiwala N, Harris E, Hwang WT and Solin LJ. Long-term outcome for mammographically detected ductal carcinoma in situ managed with breast conservation treatment: prognostic significance of reexcision. Cancer J. 2006; 12(1):25-32.

9. Cutuli B, Cohen-Solal-le Nir C, de Lafontan B, Mignotte H, Fichet V, Fay R, Servent V, Giard S, Charra-Brunaud C, Lemanski C, Auvray H, Jacquot S and Charpentier JC. Breast-conserving therapy for ductal carcinoma in situ of the breast: the French Cancer Centers' experience. Int J Radiat Oncol Biol Phys. 2002; 53(4):868-879.

10. Vicini FA, Kestin LL, Goldstein NS, Chen PY, Pettinga J, Frazier RC and Martinez AA. Impact of young age on outcome in patients with ductal carcinoma-in-situ treated with breast-conserving therapy. J Clin Oncol. 2000; 18(2):296-306.

11. Goldstein NS, Kestin L and Vicini F. Intraductal carcinoma of the breast: pathologic features associated with local recurrence in patients treated with breast-conserving therapy. Am J Surg Pathol. 2000; 24(8):1058-1067.

12. Bijker N, Peterse JL, Duchateau L, Robanus-Maandag EC, Bosch CA, Duval C, Pilotti S and van de Vijver MJ. Histological type and marker expression of the primary tumour compared with its local recurrence after breastconserving therapy for ductal carcinoma in situ. Br J Cancer. 2001; 84(4):539-544.

13. Allred DC, Clark GM, Molina R, Tandon AK, Schnitt SJ, Gilchrist KW, Osborne CK, Tormey DC and McGuire WL. Overexpression of HER-2/neu and its relationship with other prognostic factors change during the progression of in situ to invasive breast cancer. Hum Pathol. 1992; 23(9):974979.

14. Kurbel S. In search of triple-negative DCIS: tumor-type dependent model of breast cancer progression from DCIS to the invasive cancer. Tumour Biol. 2013; 34(1):1-7.

15. Horimoto Y, Tokuda E, Arakawa A, Kosaka T, Saito M and Kasumi F. Significance of HER2 protein examination in ductal carcinoma in situ. J Surg Res. 2011; 167(2):e205210.

16. Roses RE, Paulson EC, Sharma A, Schueller JE, Nisenbaum
H, Weinstein S, Fox KR, Zhang PJ and Czerniecki BJ. HER-2/neu overexpression as a predictor for the transition from in situ to invasive breast cancer. Cancer Epidemiol Biomarkers Prev. 2009; 18(5):1386-1389.

17. Bryan BB, Schnitt SJ and Collins LC. Ductal carcinoma in situ with basal-like phenotype: a possible precursor to invasive basal-like breast cancer. Mod Pathol. 2006; 19(5):617-621.

18. Clark SE, Warwick J, Carpenter R, Bowen RL, Duffy SW and Jones JL. Molecular subtyping of DCIS: heterogeneity of breast cancer reflected in pre-invasive disease. Br J Cancer. 2011; 104(1):120-127.

19. Pinder SE and Ellis IO. The diagnosis and management of pre-invasive breast disease: ductal carcinoma in situ (DCIS) and atypical ductal hyperplasia (ADH)--current definitions and classification. Breast Cancer Res. 2003; 5(5):254-257.

20. Simpson JF. Update on atypical epithelial hyperplasia and ductal carcinoma in situ. Pathology. 2009; 41(1):36-39.

21. Shah C, Wobb J, Manyam B, Kundu N, Arthur D, Wazer D, Fernandez E and Vicini F. Management of Ductal Carcinoma In Situ of the Breast: A Review. JAMA Oncol. 2016; 2(8):1083-1088.

22. Lebeau A and Kuhn T. Updates in the treatment of ductal carcinoma in situ of the breast. Curr Opin Obstet Gynecol. 2016; 28(1):49-58.

23. Julien JP, Bijker N, Fentiman IS, Peterse JL, Delledonne V, Rouanet P, Avril A, Sylvester R, Mignolet F, Bartelink $\mathrm{H}$ and Van Dongen JA. Radiotherapy in breast-conserving treatment for ductal carcinoma in situ: first results of the EORTC randomised phase III trial 10853. EORTC Breast Cancer Cooperative Group and EORTC Radiotherapy Group. Lancet. 2000; 355(9203):528-533.

24. Silverstein MJ, Poller DN, Waisman JR, Colburn WJ, Barth A, Gierson ED, Lewinsky B, Gamagami P and Slamon DJ. Prognostic classification of breast ductal carcinoma-in-situ. Lancet. 1995; 345(8958):1154-1157.

25. Bijker $\mathrm{N}$ and van Tienhoven G. Local and systemic outcomes in DCIS based on tumor and patient characteristics: the radiation oncologist's perspective. J Natl Cancer Inst Monogr. 2010; 2010(41):178-180.

26. Weng EY, Juillard GJ, Parker RG, Chang HR and Gornbein JA. Outcomes and factors impacting local recurrence of ductal carcinoma in situ. Cancer. 2000; 88(7):1643-1649.

27. Jha MK, Avlonitis VS, Griffith CD, Lennard TW, Wilson RG, McLean LM, Dawes PD and Shrimankar J. Aggressive local treatment for screen-detected DCIS results in very low rates of recurrence. Eur J Surg Oncol. 2001; 27(5):454-458.

28. de Mascarel I, Bonichon F, MacGrogan G, de Lara CT, Avril A, Picot V, Durand M, Mauriac L, Trojani M and Coindre JM. Application of the van nuys prognostic index in a retrospective series of 367 ductal carcinomas in situ of the breast examined by serial macroscopic sectioning: practical considerations. Breast Cancer Res Treat. 2000; 61(2):151-159. 
29. Ringberg A, Anagnostaki L, Anderson H, Idvall I, Ferno M and South Sweden Breast Cancer G. Cell biological factors in ductal carcinoma in situ (DCIS) of the breast-relationship to ipsilateral local recurrence and histopathological characteristics. Eur J Cancer. 2001; 37(12):1514-1522.

30. Douglas-Jones AG, Logan J, Morgan JM, Johnson R and Williams R. Effect of margins of excision on recurrence after local excision of ductal carcinoma in situ of the breast. J Clin Pathol. 2002; 55(8):581-586.

31. Leonard GD and Swain SM. Ductal carcinoma in situ, complexities and challenges. J Natl Cancer Inst. 2004; 96(12):906-920.

32. Katz A, Gage I, Evans S, Shaffer M, Fleury T, Smith FP, Flax R, Drogula C, Petrucci P and Magnant C. Sentinel lymph node positivity of patients with ductal carcinoma in situ or microinvasive breast cancer. Am J Surg. 2006; 191(6):761-766.

33. Sakr R, Bezu C, Raoust I, Antoine M, Ettore F, Darcourt J, Kerrou K, Darai E, Rouzier R and Uzan S. The sentinel lymph node procedure for patients with preoperative diagnosis of ductal carcinoma in situ: risk factors for unsuspected invasive disease and for metastatic sentinel lymph nodes. Int J Clin Pract. 2008; 62(11):1730-1735.

34. van la Parra RF, Ernst MF, Barneveld PC, Broekman JM, Rutten MJ and Bosscha K. The value of sentinel lymph node biopsy in ductal carcinoma in situ (DCIS) and DCIS with microinvasion of the breast. Eur J Surg Oncol. 2008; 34(6):631-635.

35. Shapiro-Wright HM and Julian TB. Sentinel lymph node biopsy and management of the axilla in ductal carcinoma in situ. J Natl Cancer Inst Monogr. 2010; 2010(41):145-149.

36. Sakr R, Barranger E, Antoine M, Prugnolle H, Darai E and Uzan S. Ductal carcinoma in situ: value of sentinel lymph node biopsy. J Surg Oncol. 2006; 94(5):426-430.

37. Anderson WF and Chu KC. Ductal carcinoma in situ of the breast. N Engl J Med. 2004; 351(4):399-402.

38. Kuerer HM, Albarracin CT, Yang WT, Cardiff RD, Brewster AM, Symmans WF, Hylton NM, Middleton LP, Krishnamurthy S, Perkins GH, Babiera G, Edgerton ME, Czerniecki BJ, Arun BK and Hortobagyi GN. Ductal carcinoma in situ: state of the science and roadmap to advance the field. J Clin Oncol. 2009; 27(2):279-288.
39. Kerlikowske K, Molinaro AM, Gauthier ML, Berman HK, Waldman F, Bennington J, Sanchez H, Jimenez C, Stewart $\mathrm{K}$, Chew K, Ljung BM and Tlsty TD. Biomarker expression and risk of subsequent tumors after initial ductal carcinoma in situ diagnosis. J Natl Cancer Inst. 2010; 102(9):627-637.

40. Aubele M, Mattis A, Zitzelsberger H, Walch A, Kremer M, Welzl G, Hofler H and Werner M. Extensive ductal carcinoma In situ with small foci of invasive ductal carcinoma: evidence of genetic resemblance by CGH. Int J Cancer. 2000; 85(1):82-86.

41. Baqai $\mathrm{T}$ and Shousha $\mathrm{S}$. Oestrogen receptor negativity as a marker for high-grade ductal carcinoma in situ of the breast. Histopathology. 2003; 42(5):440-447.

42. Buerger H, Otterbach F, Simon R, Poremba C, Diallo R, Decker T, Riethdorf L, Brinkschmidt C, DockhornDworniczak B and Boecker W. Comparative genomic hybridization of ductal carcinoma in situ of the breastevidence of multiple genetic pathways. J Pathol. 1999; 187(4):396-402.

43. Provenzano E, Hopper JL, Giles GG, Marr G, Venter DJ and Armes JE. Biological markers that predict clinical recurrence in ductal carcinoma in situ of the breast. Eur $\mathrm{J}$ Cancer. 2003; 39(5):622-630.

44. Moelans CB, de Weger RA, Monsuur HN, Maes AH and van Diest PJ. Molecular differences between ductal carcinoma in situ and adjacent invasive breast carcinoma: a multiplex ligation-dependent probe amplification study. Anal Cell Pathol (Amst). 2010; 33(3):165-173.

45. Wiechmann L and Kuerer HM. The molecular journey from ductal carcinoma in situ to invasive breast cancer. Cancer. 2008; 112(10):2130-2142.

46. Li CI, Malone KE, Saltzman BS and Daling JR. Risk of invasive breast carcinoma among women diagnosed with ductal carcinoma in situ and lobular carcinoma in situ, 1988-2001. Cancer. 2006; 106(10):2104-2112.

47. Wang J, Mittendorf EA, Sahin AA, Yi M, Caudle A, Hunt $\mathrm{KK}$ and $\mathrm{Wu} \mathrm{Y}$. Outcomes of sentinel lymph node dissection alone vs. axillary lymph node dissection in early stage invasive lobular carcinoma: a retrospective study of the surveillance, epidemiology and end results (SEER) database. PLoS One. 2014; 9(2):e89778. 